This is an electronic reprint of the original article. This reprint may differ from the original in pagination and typographic detail.

Author(s): Forster, Taryn; Tuononen, Heikki; Parvez, Masood; Roesler, Roland

Title: $\quad$ Characterization of $\beta$-B-Agostic Isomers in Zirconocene Amidoborane Complexes

Year: $\quad 2009$

Version:

Please cite the original version:

Forster, T., Tuononen, H., Parvez, M., \& Roesler, R. (2009). Characterization of $\beta$-BAgostic Isomers in Zirconocene Amidoborane Complexes. Journal of the American Chemical Society, 131(19), 6689-6691. https://doi.org/10.1021/ja901460y

All material supplied via JYX is protected by copyright and other intellectual property rights, and duplication or sale of all or part of any of the repository collections is not permitted, except that material may be duplicated by you for your research use or educational purposes in electronic or print form. You must obtain permission for any other use. Electronic or print copies may not be offered, whether for sale or otherwise to anyone who is not an authorised user. 


\title{
Characterization of $\beta$-B-Agostic Isomers in Zirconocene Amidoborane Complexes
}

\author{
Taryn D. Forster, Heikki M. Tuononen, ${ }^{\dagger}$ Masood Parvez, and Roland Roesler*
}

Contribution from the Department of Chemistry, University of Calgary, 2500 University Drive NW, Calgary, AB, T2N IN4 Canada, and Department of Chemistry, University of Jyväskylä, P.O. Box 35, FIN-40014 Jyväskylä, Finland

roesler@ucalgary.ca

The agostic interaction is a thoroughly documented and well understood concept in organometallic chemistry, playing an essential role in transition metal catalysis. ${ }^{1}$ In spite of the ubiquity of complexes featuring agostic interactions, to our knowledge no stereoisomers differing through the position of the C-H-M bond (agostic isomers) have been reported, although such species are believed to be responsible for determining the outcome of certain catalytic reactions, such as the stereochemistry in olefin polymerization. ${ }^{2}$ The pronounced hydridic nature of the B-H moiety renders the 3-center-2-electron B-H-M bonds considerably less elusive than the classical agostic interactions and numerous transition metal hydridoborate and related metal $\sigma$-borane complexes have been structurally characterized. ${ }^{3}$ Although the B$\mathrm{H}-\mathrm{M}$ and $\mathrm{C}-\mathrm{H}-\mathrm{M}$ interactions are based on closely related electron-sharing principles, it has been stressed that the term "agostic interaction" should be restricted to hydrocarbon derivatives, in order to emphasize that they are unusual. ${ }^{1 \mathrm{~d}}$

The $\sigma$-N-binding $\mathrm{NH}_{2}-\mathrm{BH}_{3}{ }^{-}$ligand is isoelectronic with the ethyl anion and consequently it is expected to display certain similarities in its binding properties with this simple organic group. Prompted by the potential of ammonia borane as a hydrogen source, ${ }^{4}$ amidoborane alkali and earth alkali, ${ }^{5}$ as well as transition metal complexes ${ }^{6}$ were very recently reported, although for the transition metal derivatives no structural details are yet available. We were interested in exploring the ligand properties of amidoborane, $\mathrm{NH}_{2}-\mathrm{BH}_{3}{ }^{-}$and especially in comparing its binding ability to that of the ethyl group.

Scheme 1. Synthesis of derivatives $\mathbf{1 a}, \mathbf{b}-\mathbf{3 a}, \mathbf{b}$

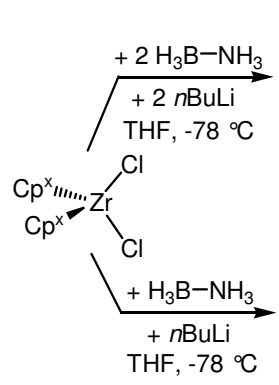

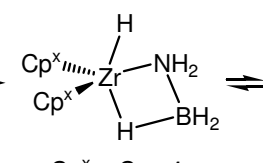

$\mathrm{Cp}^{\mathrm{x}}=\mathrm{Cp}, \mathbf{1 a}$ $\mathrm{Cp}^{*}, \mathbf{2 a}$

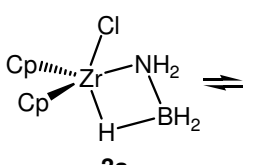

3a

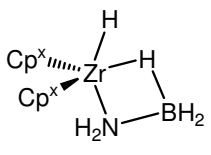

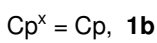
$\mathrm{Cp}^{*}, \mathbf{2 b}$<smiles>Cl[Ge]1(Cl)N[B]N1</smiles>

3b
The reaction of $\mathrm{Cp}^{\mathrm{x}_{2}} \mathrm{ZrCl}_{2}\left(\mathrm{Cp}^{\mathrm{x}}=\mathrm{Cp}, \mathrm{Cp}^{*}\right)$ with two equivalents of $\mathrm{H}_{3} \mathrm{~N}-\mathrm{BH}_{3}$ in the presence of $n \mathrm{BuLi}$ produced cleanly the zirconocene hydride complexes $\mathbf{1}$ and $\mathbf{2}$ (Scheme 1). Reaction of $\mathrm{Cp}_{2} \mathrm{ZrCl}_{2}$ with one equivalent of $\mathrm{H}_{3} \mathrm{~N}-\mathrm{BH}_{3}$ and $n \mathrm{BuLi}$ yielded 3, however, attempts to prepare $\mathrm{Cp}^{*}{ }_{2} \mathrm{Zr}(\mathrm{Cl}) \mathrm{NH}_{2} \mathrm{BH}_{3}$ (4) produced only mixtures of $\mathbf{2}$ and unreacted $\mathrm{Cp}^{*}{ }_{2} \mathrm{ZrCl}_{2}$. A plausible mechanism for the formation of $\mathbf{1}$ via the intermediate $\mathbf{3}$ would involve salt metathesis and formation of the sterically encumbered complex $\mathrm{Cp} 2 \mathrm{Zr}\left(\mathrm{NH}_{2} \mathrm{BH}_{3}\right)_{2}$, followed by spontaneous $\beta$-hydride elimination, which is common for metal ethyl derivatives. The steric strain provided by the bulky $\mathrm{Cp}^{*}$ ligands in $\mathbf{4}$ could promote $\beta$-hydride elimination with formation of $\mathrm{Cp}^{*}{ }_{2} \mathrm{Zr}(\mathrm{H}) \mathrm{Cl}$, which would undergo further salt metathesis to yield the sterically less encumbered complex 2. All complexes were isolated as colorless crystalline solids. The expected by-products of $\beta$-hydride elimination, cyclic borazane oligomers or open-chain polymers, were not identified. ${ }^{7}$

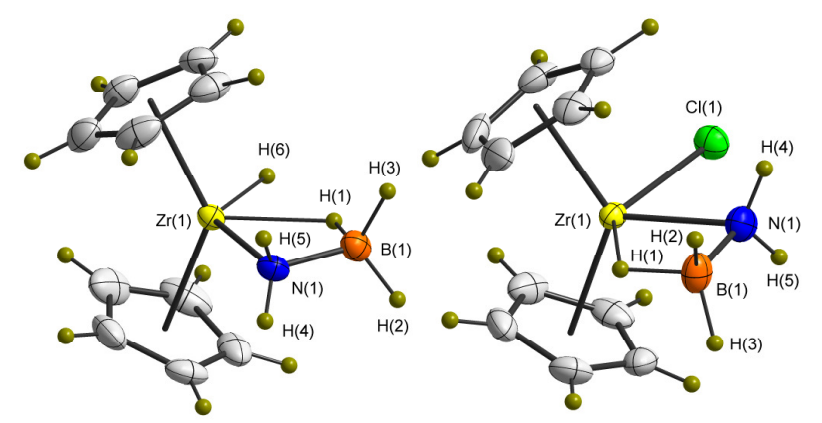

Figure 1. Solid-state molecular structures of $\mathbf{1 b I}$ (left) and $\mathbf{3 a}$ (right) with thermal ellipsoids at $50 \%$ probability. Selected bond lengths $(\AA)$ and angles (deg); the values for the polymorph $\mathbf{1 b I I}$ are reported in curly brackets and the calculated values in square brackets: $\mathbf{1 b I}\{\mathbf{1 b I I}\} \mathrm{Zr}-\mathrm{H}(6)$ 1.71(4) $\{1.74(3)\} \quad[1.823], \mathrm{Zr}-\mathrm{N}$ 2.286(4) \{2.284(2)\} [2.297], $\mathrm{Zr} \cdots \mathrm{B}$ $2.665(5)\{2.657(2)\}[2.643], \mathrm{N}-\mathrm{B} 1.539(7)\{1.531(3)\}[1.544], \mathrm{N}-\mathrm{H}$ $0.81(5), 0.81(6)\{0.84(3), 0.86(3)\} \quad[1.008], B-\mathrm{H}_{\text {term }} 1.09(5), 1.10(4)$ $\{1.11(3), 1.11(3)\}$ [1.208], B-H(1) 1.22(4) \{1.24(4)\} [1.301], $\mathrm{Zr}-\mathrm{H}(1)$ $2.02(4)\{1.98(2)\}[2.004], \mathrm{H}(6)-\mathrm{Zr}-\mathrm{N}$ 125.1(14) \{123.0(8)\} [122.85], ZrN-B 86.0(3) \{85.86(12)\} [84.55], N-B-H(1) 105(2) \{103.9(11)\} [107.21], $\mathrm{Zr}-\mathrm{H}(1)-\mathrm{B}$ 108(2) \{109(2)\} [104.19]; 3a Zr-Cl 2.5742(8) [2.520], Zr-N

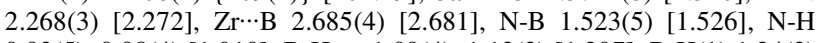
$0.93(5), 0.98(4)$ [1.010], B-Hterm 1.09(4), 1.13(3) [1.207], B-H(1) 1.24(3) [1.306], Zr-H(1) 2.02 (3) [2.015], Cl-Zr-N 78.68(8) [78.73], Zr-N-B 87.89(19) [87.49], N-B-H(1) 102.8(15) [104.13], Zr-H(1)-B 108(2) [105.69].

${ }^{1} \mathrm{H}$ and ${ }^{13} \mathrm{C}$ NMR spectra of the compounds $\mathbf{1}-\mathbf{3}$ in benzene$\mathrm{d}_{6}$, toluene- $\mathrm{d}_{8}$, and THF- $\mathrm{d}_{8}$ feature all the signals expected for either the $\mathrm{Cp}$ or the $\mathrm{Cp}^{*}$ ligands in sets of two, in good agreement with the presence of two isomers for each compound. The relative intensities of the signals indicate different ratios between the two isomers, which are strongly solvent dependent but show little temperature dependence. The pair of ${ }^{1} \mathrm{H}$ resonances corresponding to the zirconium hydride, one for each isomer, appear between $3.12-3.61 \mathrm{ppm}$ for $\mathbf{1}$ and $4.08-4.15 \mathrm{ppm}$ for $\mathbf{2}$, slightly upfield from the typical values observed for terminal zirconium hydrides. ${ }^{8}$ Two broad ${ }^{1} \mathrm{H}$ NMR resonances corresponding to the $\mathrm{NH}_{2}$ groups of $\mathbf{1}(0.10-1.41 \mathrm{ppm}), \mathbf{2}(-0.10-0.40 \mathrm{ppm})$ and $\mathbf{3}(1.48-2.76$ ppm) are generally observed but occasionally these resonances coincide. The very broad quartet signals corresponding to the $\mathrm{BH}_{3}$ protons in the two isomers of $\mathbf{1}, \mathbf{2}$ and $\mathbf{3}$, respectively, overlap at room temperature between -0.15 and $0.44 \mathrm{ppm}$. Also at room temperature, the ${ }^{11} \mathrm{~B}$ NMR spectra of $\mathbf{1}, \mathbf{2}$ and $\mathbf{3}$ all feature two 
distinct, sharp quartet resonances around $-34,-31$ and $-23 \mathrm{ppm}$ respectively, with ${ }^{1} \mathrm{~J}_{\mathrm{BH}}=88-94 \mathrm{~Hz}$. This is comparable to the value of $92 \mathrm{~Hz}$ observed for ammonia borane, confirming that all three hydrogen atoms in each isomer are equivalent on NMR time scale.

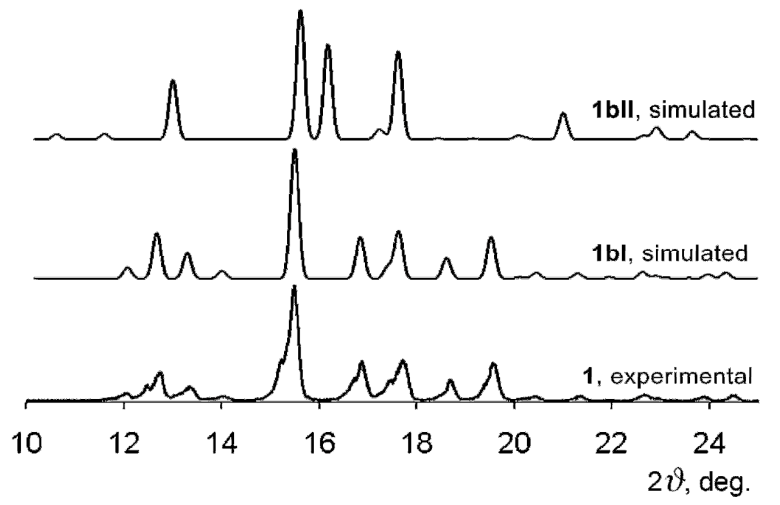

Figure 2. Simulated and experimental powder X-ray pattern of $\mathbf{1}$.

Single crystal X-ray diffraction for samples of $\mathbf{1}$ revealed two coexisting polymorphs, $\mathbf{1 b I}$ and $\mathbf{1 b I I}$. Their metric parameters are very similar and only the former will be discussed. The crystal structures of $\mathbf{2 b}$ and $\mathbf{3 a}$ were also determined, however, the former suffered from significant disorder of the $\mathrm{Cp}^{*}$ ligands, preventing the location of the hydrogen atoms even at $-150{ }^{\circ} \mathrm{C}$, and will not be discussed. The molecular structure of $\mathbf{2 b}$ is nevertheless similar to the structure of $\mathbf{1 b}$. The most important feature of all structures is the chelating $\mathrm{NH}_{2} \mathrm{BH}_{3}{ }^{-}$ligand, which binds to the metal through a $\mathrm{Zr}-\mathrm{N}$ bond and a $\mathrm{Zr}-\mathrm{H}-\mathrm{B}$ bridge. The resulting planar MBNH ring has been observed as a structural element in several main group ${ }^{5 e, 9}$ and transition metal complexes, ${ }^{10}$ among them one zirconium derivative, which contained the $\mathrm{Cp}_{2} \mathrm{ZrCl}$ fragment ( $\mathrm{Zr}$ -

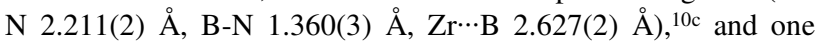
derivative that featured a tetra-coordinated nitrogen (B-N 1.52(4) A). ${ }^{10 a, b}$ Very recently, a nickel(II) complex, (N-heterocyclic carbene) $\mathrm{Ni}(\mathrm{H}) \mathrm{NH}_{2} \mathrm{BH}_{3}$, featuring the amidoborane ligand in a very similar bonding environment was proposed as an intermediate in the catalytic decomposition of ammonia borane. ${ }^{11}$ The coordination of the $\mathrm{NH}_{2} \mathrm{BH}_{3}$ fragment is strikingly similar to that of the isoelectronic ethyl group in the seven $\beta$-agostic ethylmetal complexes that have been structurally characterized so far. ${ }^{12}$ The metric parameters in the only zirconium derivative, $\left(\eta^{5}\right.$ $\left.\mathrm{MeC}_{5} \mathrm{H}_{4}\right)_{2} \mathrm{Zr}\left(\mathrm{PMe}_{3}\right) \mathrm{Et}^{+},{ }^{12 \mathrm{~d}}$ are similar to those observed in $\mathbf{1 b}$ and 3a $\left(\mathrm{Zr}-\mathrm{C}_{\alpha} 2.290(9) \AA, \mathrm{C}_{\alpha}-\mathrm{C}_{\beta} 1.47(2) \AA, \mathrm{Zr}^{\cdots} \mathrm{C}_{\beta} 2.629(9) \AA\right.$, vs. $\mathrm{Zr}-$ $\mathrm{N} 2.268(3)$ - 2.286(4) $\AA$, B-N 1.523(5) - 1.539(7) $\AA, \mathrm{Zr} \cdots \mathrm{B}$ $2.657(2)$ - 2.685(4) $\AA$.). The slight shortening of the B-N bond upon coordination ( $v s$. the $\mathrm{B}-\mathrm{N}$ bond in ammonia borane, 1.597(3) $\AA)^{13}$ mirrors the shortening of the $\mathrm{C}_{\alpha}-\mathrm{C}_{\beta}$ bond in $\beta$ agostic ethyl complexes (vs. the C-C bond in ethane, 1.532(2) $\AA) .{ }^{14}$ One of the structural trademarks of the $\beta$-agostic interaction in these derivatives is the unusually narrow $\mathrm{M}-\mathrm{C}_{\alpha}-\mathrm{C}_{\beta}$ angle (74.3 $84.5^{\circ}$ ), with the early metals $\mathrm{Ti}$ and $\mathrm{Zr}$ situated at the wider end of the range and the late metals $\mathrm{Co}, \mathrm{Ni}$ and $\mathrm{Pt}$ at the narrow end. With Zr-N-B angles of $85.9-87.9^{\circ}$, complexes $\mathbf{1 b}$ and 3a fit the model very well, and the term " $\beta$-B-agostic" was chosen to describe the bonding in these compounds in order to emphasize the similarity to $\beta$-agostic ethyl complexes.

The vibrational spectra of $\mathbf{1}, \mathbf{2}$ and $\mathbf{3}$ confirmed the findings of the structural measurements, exhibiting characteristic vibrations for terminal and bridging $\mathrm{BH}$ bonds at $2397-2304$ and 1899 $1792 \mathrm{~cm}^{-1}$, respectively. ${ }^{15}$ In addition, $\mathrm{NH}$ vibrations were observed at $3430-3280 \mathrm{~cm}^{-1}$ and $\mathrm{Zr}-\mathrm{H}$ vibrations (in 1 and 2) at 1553 and $1531 \mathrm{~cm}^{-1}$.

Like in other pentacoordinate zirconocene complexes (considering $\mathrm{Cp}$ as a mondodentate ligand), the $\mathrm{Zr}-\mathrm{H}$ and $\mathrm{Zr}-\mathrm{Cl}$ bond in $\mathbf{1 b}$ and $\mathbf{3} \mathbf{a}$, respectively, is situated in the plane of the $\mathrm{ZrNBH}$ ring, which in turn lies symmetrically between the cyclopentadienyl rings. This raises the possibility for the existence of two stereoisomers, $\mathbf{a}$ and $\mathbf{b}$, and in the solid state the metal hydride in $\mathbf{1 b}$ is indeed situated trans to the nitrogen atom while the chloride in $\mathbf{3 a}$ is situated trans to the boron atom. The presence of pairs of resonances with solvent-dependent relative ratios in the NMR spectra of 1, 2 and $\mathbf{3}$ indicates that, for each compound, the two isomers coexist and are in equilibrium. The cross-peaks for the Cp protons in the EXSY NMR spectra of $\mathbf{1}$ and $\mathbf{3}$ in toluene- $\mathrm{d}_{8}$ confirmed this supposition and the exchange rates were estimated at $0.27 \mathrm{~s}^{-1}$ at $20{ }^{\circ} \mathrm{C}$ and $0.05 \mathrm{~s}^{-1}$ at $-20{ }^{\circ} \mathrm{C}$ for the former and $0.01 \mathrm{~s}^{-1}$ at $20{ }^{\circ} \mathrm{C}$ for the latter. Powder X-ray diffraction showed that $\mathbf{1 b I}$ is the main constituent of $\mathbf{1}$ in the solid state, with no detectable amount of $\mathbf{1 b I I}$ being present (Figure 2). No other major crystalline constituents were observed, and elemental analysis proved the purity of the sample.

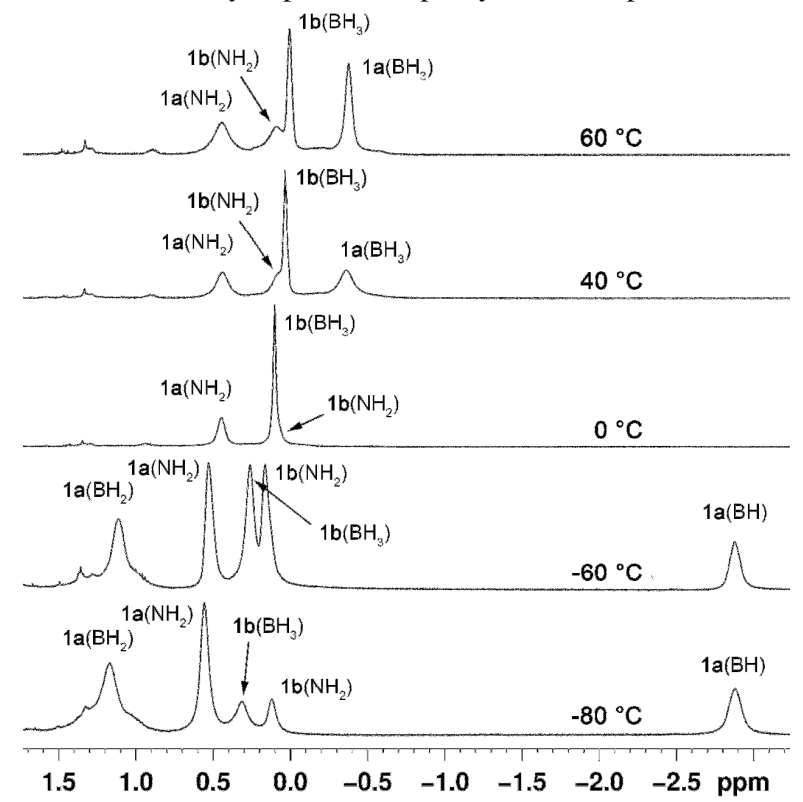

Figure 3. Variable temperature ${ }^{1} \mathrm{H}\left\{{ }^{11} \mathrm{~B}\right\}$ NMR spectra of $\mathbf{1}$ in toluene-d8, showing the area featuring the resonances corresponding to the protons in the $\mathrm{NH}_{2} \mathrm{BH}_{3}$ ligand.

A variable-temperature boron-decoupled ${ }^{1} \mathrm{H}$ NMR study of $\mathbf{1}$ in toluene- $\mathrm{d}_{8}$ allowed for a more precise assignment of the resonances corresponding to the hydrogen atoms attached to boron (Figure 3). At $60{ }^{\circ} \mathrm{C}$, these hydrogen atoms are equivalent on the NMR time scale and generate a sharper resonance at 0.01 ppm (1b) and a broader one at $-0.38 \mathrm{ppm}(\mathbf{1 a})$. The resonance at $0.01 \mathrm{ppm}$ broadens upon cooling and shifts slightly downfield, reaching $0.31 \mathrm{ppm}$ at $-80{ }^{\circ} \mathrm{C}$. The broader resonance at $-0.38 \mathrm{ppm}$ coalesces around $0{ }^{\circ} \mathrm{C}$ and splits upon further cooling into two signals in a $2: 1$ ratio at 1.17 and $-2.88 \mathrm{ppm}$ (at $-80{ }^{\circ} \mathrm{C}$ ), corresponding to the terminal $\left(\mathrm{BH}_{2}\right)$ and bridging $(\mathrm{B}-\mathrm{H}-\mathrm{Zr})$ hydrogen atoms, respectively, in 1a. This behavior indicates a noticeably lower free enthalpy of activation with respect to the rotation of the $\mathrm{BH}_{3}$ moiety around the $\mathrm{BN}$ bond in $\mathbf{1 b}$ than in $\mathbf{1 a}$, where $\Delta \mathrm{G}^{\ddagger} 273$ was estimated using NMR data to be $48 \mathrm{~kJ} \cdot \mathrm{mol}^{-1}$. A lower free enthalpy of activation would be expected in $\mathbf{1 b}$, where 
the $\mathrm{BH}_{3}$ moiety experiences less steric strain from the $\mathrm{Cp}$ groups when compared to 1a, in which the tilted $\mathrm{Cp}$ groups sandwich the $\mathrm{BH}_{3}$ moiety more tightly. A computational study confirmed this supposition, estimating the enthalpy of activation with respect to the rotation of the $\mathrm{BH}_{3}$ moiety around the $\mathrm{BN}$ bond at $46 \mathrm{~kJ} \cdot \mathrm{mol}^{-1}$ in $\mathbf{1 a}$ and $19 \mathrm{~kJ} \cdot \mathbf{m o l}^{-1}$ in $\mathbf{1 b}$, allowing for the correlation between the solid-state structures and the NMR signals. Between -80 and $90{ }^{\circ} \mathrm{C}$, NMR reveals that $\mathbf{1 b}$ starts to crystallize out of the toluene$\mathrm{d} 8$ solution, in good agreement with the results of the solid state structural studies.

The low-temperature ${ }^{1} \mathrm{H}$ NMR spectra of 1a,b featured broad signals corresponding to the $\mathrm{BH}$ protons, preventing the determination of the ${ }^{1} \mathrm{~J}_{\mathrm{BH}}$ coupling constant. Similarily, the ${ }^{1} \mathrm{~J}_{\mathrm{BH}}$ coupling was not resolved in the low-temperature ${ }^{11} \mathrm{~B}$ NMR spectra. COSY NMR was used for the assignment of the peaks in the ${ }^{1} \mathrm{H}$ NMR spectra of 1a,b. Cross-peaks were observed between the resonances assigned to the terminal zirconium hydride and those corresponding to the $\mathrm{NH}_{2}$ protons, as well as to those corresponding to the bridging $\mathrm{BH}$ and temperature-averaged $\mathrm{BH}_{3}$ protons in both isomers. The scalar coupling confirmed that the $\beta$ B-agostic interaction is preserved in solution in both $\mathbf{1 a}$ and $\mathbf{1 b}$. An open-chain isomer would be expected to be considerably higher in energy and its relative concentration would be expected to be strongly temperature dependent. A computational analysis showed the structurally characterized derivatives $\mathbf{1 b}$ and $\mathbf{2 b}$ to be, in vacuum, energetically on par with their isomers $\mathbf{1 a}$ and $\mathbf{2 a}$, respectively, with the energy differences between them being less than the expected accuracy of the employed method. Under the same conditions, the crystallized isomer 3a was $c a .25 \mathrm{~kJ} \cdot \mathrm{mol}^{-1}$ more stable than $\mathbf{3 b}$. In all cases, the energy minima were very shallow because of the low energy barrier for the rotation of the $\mathrm{Cp} / \mathrm{Cp}^{*}$ groups and, more importantly, the improbable open-chain isomers featuring monodentate amidoborane ligands were not found to constitute stable minima on the potential energy surface.

In conclusion, we report herein the first structural characterization of transition metal amidoborane complexes. All complexes feature chelating $\mathrm{NH}_{2} \mathrm{BH}_{3}{ }^{-}$ligands binding through a $\mathrm{Zr}-\mathrm{N}$ bond and a classical $\mathrm{Zr}-\mathrm{H}-\mathrm{B}$ bridge and their structural and spectroscopic properties mirror the properties of their isoelectronic $\beta$-agostic ethyl analogs. The relative position of the amidoborane ligand with respect to the chloride or hydride ligand on zirconium gives rise to stereoisomers that have not been characterized in the chemistry of less robust $\beta$-agostic derivatives. The parallel between the more stable $\beta$-B-agostic amidoborane complexes and their isoelectronic $\beta$-agostic ethyl analogs should allow for a better understanding of both systems. In addition, the structure and dynamic of the derivatives characterized herein is relevant to the thriving field of catalytic hydrogen generation from ammonia borane.

Acknowledgment. This work was supported by the Natural Sciences and Engineering Research Council of Canada, the Canada Foundation for Innovation, the Academy of Finland and the Alberta Science and Research Investments Program. We thank Dr. Venkataraman Thangadurai for support with powder Xdiffraction experiments, Dr. Farideh Jalilehvand for the Raman measurements and Dr. Tom Ziegler for helpful discussions. TDF thanks the NSERC for a CGS-D scholarship.

Supporting Information Available: Experimental details and complete spectroscopic data for $\mathbf{1}-\mathbf{3}$, crystallographic details including CIF files for $\mathbf{1 b I}, \mathbf{1 b I I}$, and 3a, powder X-ray diffraction data for $\mathbf{1}$, and computational details for $\mathbf{1}-\mathbf{4}$. This material is available free of charge via the internet at http://pubs.acs.org. $\dagger \quad$ University of Jyväskylä

References

(1) (a) Brookhart, M.: Green, M. L. H. J. Organomet. Chem. 1983, 250, 395-408. (b) Brookhart, M.; Green, M. L. H.; Wong, L. L. Prog. Inorg. Chem. 1988, 36, 1-124. (c) Scherer, W.; McGrady, G. S. Angew. Chem. Int. Ed. 2004, 43, 1782-1806. (d) Brookhart, M.; Green, M. L. H.; Parkin, G. Proc. Natl. Acad. Sci. U.S.A. 2007, 104, 6908-6914.

(2) (a) Fan, L.; Harrison, D.; Deng, L.; Woo, T. K.; Swerhone, D.; Ziegler, T. Can. J. Chem. 1995, 73, 989-998. (b) Grubbs, R. H.; Coates, G. W. Acc. Chem. Res. 1996, 29, 85-93.

(3) (a) Marks, T. J., Kolb, J. R. Chem. Rev. 1977, 77, 263-293. (b) Greenwood, N. N.; Coord. Chem. Rev. 2002, 226, 61-69. (c) Lin, Z. Struct. Bond. 2008, 130, 123-148. (d) Besora, M.; Lledós, A. Struct. Bond. 2008, 130, 149-202. (e) Alcaraz, G.; Sabo-Etienne, S. Coord. Chem. Rev. 2008, 252, 2395-2409.

(4) (a) Marder, T. B. Angew. Chem., Int. Ed. 2007, 46, 8116-8118. (b) Stephens, F. H.; Pons, V.; Baker, R. T. Dalton Trans. 2007, 25, 26132626. (c) Hamilton, C. W.; Baker, R. T.; Staubitz, A.; Manners, I. Chem. Soc. Review. 2009, 38, 279-293.

(5) (a) Myers, A. G.; Yang, B. H.; Kopecky, D. J. Tetrahedron Lett. 1996, 37, 3623-3626. (b) Diyabalanage, H. V. K.; Shrestha, R. P.; Semelsberger, T. A.; Scott, B. L.; Bowden, M. E.; Davis, B. L.; Burrell, A. K. Angew. Chem., Int. Ed. 2007, 46, 8995-8997. (c) Xiong, Z.; Yong, C. K.; Wu, G.; Chen, P.; Shaw, W.; Karkamkar, A.; Autrey, T.; Jones, M. O.; Johnson, S. R.; Edwards, P. P.; David, W. I. F. Nature Mat. 2008, 7, 138-141. (d) Xiong, Z.; Wu, G.; Chua, Y. S.; Hu, J.; He, T.; Xu, W.; Chen, P. Energy Environ. Sci. 2008, 1, 360-363. (e) Spielmann, J.; Jansen, G.; Bandmann, H.; Harder, S. Angew. Chem., Int. Ed. 2008, 47, Jansen, G.; Bandmann, H.; Harder, S. Angew. Chem., Int. Ed. 2008, 47, 130, $14834-14839$.

(6) (a) Shrestha, R. L.; Diyabalanage, H. V. K.; Semelsberger, T. A.; Scott, B. L.; Burrell, A. K. at the 236th ACS National Meeting, Philadelphia, PA, United States, August 2008. (b) Baker, R. T. at the 13th International Conference on Boron Chemistry, Platja d'Aro, Spain, September 2008. (c) Burrell, A. K.; Davis, B. J.; Thorn, D. L.; Gordon, J. C.; Baker, R. T.; Semelsberger, T. A.; Tumas, W.; Diyabalanage, H. V. K.; Shrestha, R. P. U.S. Patent Appl. 0311017 A1, 2008.

(7) (a) Corfield, P. W. R.; Shore, S. G. J. Am. Chem. Soc., 1973, 95, 14801487. (b) Shaw, W. J.; Linehan, J. C.; Szymczak, N. K.; Heldebrant, D. J.; Yonker, C.; Camaioni, D. M.; Baker, R. T.; Autrey T. Angew. Chem., Int. Ed. 2008, 47, 7493-7496. (c) Pons, V.; Baker, R. T. Angew. Chem., Int. $E d$. 2008, 47, 9600-9602.

(8) (a) Manriquez, J. M.; McAlister, D. R.; Sanner, R. D.; Bercaw, J. E. J. Am. Chem. Soc. 1978, 100, 2716-2724. (b) Kot, W. K.; Edelstein, N. M.; Zalkin, A. Inorg. Chem. 1987, 26, 1339-1341. (c) Lee, H.; Desrosiers, P. J.; Guzei, I.; Rheingold, A. L.; Parkin, G. J. Am. Chem. Soc. 1998, 120, 3255-3256. (d) Chen, X.; Liu, S.; Plečnik, C. E.; Liu, F.-C. Fraenkel, G.; Shore, S. G. Organometallics, 2003, 22, 275-283. (e) Liu, F.-C.; Chen, J.-H.; Chen, S.-C.; Chen, K.-Y.; Lee, G.-H.; Peng, S.-M. J. Organomet. Chem. 2005, 690, 291-300.

(9) (a) Nöth, H.; Thomas, S.; Schmidt, M. Chem. Ber. 1996, 129, 451-458. (b) Dornhaus, F., Bolte, M. Acta Cryst. 2007, E63, m39-m40. (c) Spielmann, J.; Harder, S. J. Am. Chem. Soc. 2009, 131, 5064-5065.

(10) (a) Fachinetti, G.; Floriani, C.; Mellini, M.; Merlino, S. Chem. Commun. 1976, 300-301. (b) Dell'Amico, G.; Marchetti, F.; Floriani, C. J. Chem. Soc., Dalton Trans. 1982, 2197-2202. (c) Männig, D.; Nöth, H.; Schwartz, M.; Weber, S.; Wietelmann, U. Angew. Chem., Int. Ed. Engl. 1985, 24, 998-999. (d) Binger, P.; Sandmeyer, F.; Krüger, C. Organometallics, 1995, 14, 2969-2976. (e) Fryzuk, M. D.; MacKay, B. A.; Johnson, S. A.; Patrick B. O. Angew. Chem., Int. Ed. 2002, 41, 37093712. (f) Hillier, A. C.; Fox, T.; Schmalle H. W.; Berke H. J. Organomet. Chem. 2003, 669, 14-24. (g) MacKay, B. A.; Johnson, S. Arganomet. Chem. 2003, 669, , 14-24. (g) Mackay, B. A.; Johnso

(11) Zimmerman, P. M.; Paul, A.; Zhang, Z.; Musgrave, C. B. Angew. Chem. Int. Ed. 2009, 48, 2201-2205.

(12) (a) Dawoodi, Z.; Green, M. L. H.; Mtetwa, V. S. B.; Prout, K. J. Chem. Soc., Chem. Commun. 1982, 802-803. (b) Cracknell, R. B.; Orpen, A. G.; Spencer, J. L. J. Chem. Soc., Chem. Commun. 1984, 326-328. (c) Dawoodi, Z.; Green, M. L. H.; Mtetwa, V. S. B.; Prout, K.; Schultz, A. J.; Williams, J.M.; Koetzle T.F. J. Chem. Soc., Dalton Trans. 1986, 1629-1637. (d) Jordan, R. F. Bradley, P. K. Baenziger, N C.: LaPointe, R. E. J. Am. Chem. Soc. 1990, 112, 1289-1291. (e) Conroy-Lewis, F. M.; Mole, L.; Redhouse, A. D.; Litster, S. A.; Spencer, J. L. J. Chem. Soc., Chem. Commun. 1991, 1601-1603. (f) Carr, N.; Mole, L.; Orpen, A. G.; Spencer, J. L. J. Chem. Soc., Dalton Trans. 1992, 2653-2662. (g) Fryzuk, M. D.; Johnson, S. A.; Rettig, S. J. J. Am. Chem. Soc. 2001, 123, 1602-1612. (h) Kogut, E.; Zeller, A.; Warren, T. H.; Strassner, T. J. Am. Chem. Soc. 2004, 126, 11984-11994.

(13) (a) Hughes, E. W. J. Am. Chem. Soc. 1956, 78, 502-503. (b) Klooster, W. T.; Koetzle, T. F.; Siegbahn, P. E. M.; Richardson, T. B.; Crabtree R. H. J. Am. Chem. Soc. 1999, 121, 6337-6343. (c) Bowden, M. E.; Gainsford, G. J.; Robinson W. T. Aust. J. Chem. 2007, 60, 149-153.

(14) van Nes, G. J. H.; Vos, A. Acta Cryst. 1978, 34B, 1947-1956

(15) (a) Smith, J.; Seshadri, K. S.; White, D. J. Mol. Spectrosc. 1973, 45, 327-337. (b) Hess, N. J.; Bowden, M. E.; Parvanov, V. M.; Mundy, C.; Kathmann, S. M.; Schenter, G. K.; Autrey, T. J. Chem. Phys. 2008, 128 , 034508-1-034508-9. 